\title{
IN VITRO BIOCHEMICAL VARIABILITY OF SUSCEPTIBLE AND NON SUSCEPTIBLE ISOLATES OF TRICHOMONAS VAGINALIS TO METRONIDAZOLE
}

\author{
Syy \\ Marwa M. Hamoudaa, Aida A. Abdel-Magieda, Goman A. El-Rahman \\ El-Ganynia, Salwa M. Abo El-Khairb, Nora L. El-Tantawya, \\ Alaa Mosbahc, El-Said I. El-Kholya.

\begin{abstract}
Trom
a: Department of Parasitology, Faculty of Medicine, Mansoura University, 35516, Egypt

b: Department of Biochemistry, Faculty of Medicine, Mansoura University, 35516, Egypt

c: Department Of obstetrics and Gynecology, Faculty of Medicine, Mansoura University, Egypt.
\end{abstract}

\begin{abstract}
Background: Although metronidazole is the drug of choice for treatment of trichomoniasis, resistant Trichomonas vaginalis isolates have been identified. Aim of the study: So, the aim of our study is to investigate the in vitro susceptibility of $T$. vaginalis against metronidazole in our locality.
\end{abstract}

Methods: Vaginal swabs were collected from 420 cases attending the outpatients' clinics of the gynecology department, Mansoura university hospital. The patients were subjected to wet mount smear examination and Giemsa staining followed by culture on modified Diamond's media. In vitro susceptibility testing was done for 49 trichomonas vaginalis positive cases to determine minimal lethal concentration (MLC) of metronidazole in each case.

Results: Most susceptible isolates (34.7\%) were dead at MLC $1 \mu \mathrm{g} \backslash \mathrm{ml}$ followed by MLC $2 \mu \mathrm{g} \mathrm{Iml}$ at which 8 $(16.3 \%)$ isolates were killed, followed by $6(12.2 \%)$ isolates at $4 \mu \mathrm{g} / \mathrm{ml}, 7$ isolates $(14.2 \%)$ at $8 \mu \mathrm{g} / \mathrm{ml}, 4$ isolates $(8.1 \%)$ at $16 \mu \mathrm{g} / \mathrm{ml}$, and 3 $(6.1 \%)$ isolates at $32 \mu \mathrm{g} / \mathrm{ml}$ while in resistant isolates 2 were killed at concentration $64 \mu \mathrm{g} / \mathrm{ml}$ and 2 iso- 
lates were sensitive at concentration $128 \mu \mathrm{g} \backslash \mathrm{ml}$.

Conclusion: In our locality, most isolates were susceptible to low dose of metronidazole (lower than or equal $32 \mu \mathrm{g} / \mathrm{ml}$ )with few resistant isolates that could be explained by development of drug resistance in future.

Keywords: Trichomonas vaginalis, Metronidazole, Resistance, Susceptibility, in vitro biochemical testing.

\section{INTRODUCTION}

Trichomoniasis, the clinical disease refers to the $T$. vaginalis pathogen, has become the most prevalent non-viral sexually transmitted infection (STI) in the United States [1] . The worldwide incidence of trichomoniasis was estimated to be 276.4 million new cases per year in 2008 [2]. In Egypt, the reported rate of prevalence ranges from $5 \%$ to $79.16 \%$ [3]

In women, trichomoniasis has a wide spectrum of clinical presentations ranging from asymptomatic to acute, or subacute vaginitis with malodorous vaginal discharge [4]. Other symptoms include dysuria, dyspareunia, or vulvovaginal soreness. Common signs include vulvovaginal erythema, frothy yellowish-gray vaginal discharge, increase $\mathrm{pH}$ of the vagina $(>6)$, and rarely a strawberry cervix [5]. Infection may be complicated with preterm labor and increased perinatal morbidity [6].

Diagnosis of $T$. vaginalis is established by the traditional wet mount test, in which "corkscrew" motility is observed [7]. Culture has long been the gold standard for diagnosing $\mathrm{T}$. vaginalis infection, with a sensitivity range from $85-95 \%$ [8]. Other used methods for diagnosis include enzyme-linked immunosorbent assay, staining methods, latex agglutination, and nucleic acid amplification tests. [9]

Metronidazole is the drug of choice for the treatment of trichomoniasis. A single oral dose of 2-g achieves a cure rate of $90-95 \%$ [10]. Low-level resistance of $T$. vaginalis to metronidazole has been reported in a range of $2-5 \%[11]$.

Metronidazole resistance is defined clinically as failure to cure infection after two successive courses 
of treatment. Once other causes of treatment failure have been ruled out including medication noncompliance and reinfection, the possibility of a resistant vaginal trichomoniasis must be considered [12]. Although various therapeutic regimens have been developed and recorded, there is no consensus on therapy for metronidazole resistant vaginal trichomoniasis [13].

The aim of this work is to detect the magnitude of $T$. vaginalis resistance.to metronidazole in our locality and its implications on patients' outcome.

\section{SUBJECTS \& METHODS}

\subsection{Study design}

The study was carried out in Medical Parasitology Department Faculty of Medicine, Mansoura University and Gynecology outpatient clinic of Mansoura University Hospital, during the period from December 2013 to February 2016.

\subsection{Patients' selection}

A total of 320 symptomatic female patients were included in this study. Another 100 patients were included in the study screening for trichomonas vaginalis in non-symptomatic patient.
Criteria for symptomatic patients: Women in their childbearing age (18:45years) who complained of vaginal discharge of any type, itching, burning sensation or both, and with any other gynecological manifestations suggestive of trichomoniasis such as dyspareunia and or dysuria.

Criteria for asymptomatic patients: Patients matching the same age group were included.

Exclusion criteria: Pregnant women, during menstruation, vaginal douching for at least 2-3 days before the day of examination.

\subsection{Data and sample collection}

An informed written consent was obtained from each patient after explanation of the procedure and all experiments have been examined and approved by Mansoura University ethics committee.

History taking included age, parity, presenting symptoms such as vaginal discharge, bad odor, itching, dysuria, dyspareunia, burning sensation and post coital bleeding, also obstetric history as regard delivery of low birth weight infant and preterm delivery

MANSOURA MEDICAL JOURNAL 
Clinical examination involved per vaginal (PV) non lubricated dry sterile speculum for each case to obtain two vaginal swab.

\subsection{Methods}

Two Vaginal specimens were collected using sterile cotton swab from the posterior fornix during speculum examination to be examined as following : one swab for wet mount microscopic examination according to Mahmoud et al [14]. Swab was mixed in 1:2 $\mathrm{ml}$ phosphate buffer saline solution and then examined microscopically under dark ground illumination for evidence of motile trichomonas vaginalis within $0.5-3$ hours after sampling time ( Figure 1).

The other swab used for culture of $\mathrm{T}$. vaginalis on Modified Diamond medium [15]. The medium was supplemented with $10 \%$ heat inactivated bovine serum. Microorganisms were eliminated by the aid of sodium penicillin G, streptomycin sulphate, amphotericin. All strains were maintained in $10 \mathrm{ml}$ screw cap glass tube at $37^{\circ} \mathrm{C}$. The detection of $\mathrm{T}$. vaginalis trophozoites was considered if object of approximately 7 to $10 \mu \mathrm{m}$ in diameter was observed showing the characteristic jerky motility (Figure 2).
Subculture was usually done every $48 \mathrm{~h}$ by adding $0.3 \mathrm{ml}$ from the suspension to fresh tube containing culture media [16].

\subsection{In vitro resistance tests}

We used metronidazole vial (Amerizole) (Amriya for pharmaceutical industries) each $100 \mathrm{ml}$ contain $500 \mathrm{mg}$ metronidazole. Drug susceptibility test was carried out by aerobic tube assay method as described by Kulda et al [17]. Metronidazole was used in our study in a serial dilution at concentration of $1,2,4,8,16,32,64,128,256 \mu \mathrm{g} / \mathrm{ml}$. The assay was run twice with drug free media as standard control. Haemocytometer count was made with $48 \mathrm{~h}$ old culture of trichomonads to obtain the desired number $\left(1 \times 10^{4}\right.$ trophozoite $/ \mathrm{ml}$ ).

Each one of 9 culture tubes were inoculated with $10^{4}$ trophozoites, and the different concentrations of the drug were added to each isolate with a final volume of $2 \mathrm{ml}$ per tube and incubated at $37^{\circ} \mathrm{C}$ under aerobic conditions for 48 hours. The control tubes for each isolate were incubated simultaneously under the same conditions, the drug susceptibility of the different isolates was recorded 
by determining the minimal lethal concentration (MLC), which is defined as the lowest drug concentration at which no motile organisms were observed [17, 18]. The viability of the parasite was assessed by reculture of the inoculate previously exposed to the drug in drug-free media [17]. Metronidazole resistance case was defined as aerobic MLC $\geq$ $50 \mu \mathrm{g} / \mathrm{ml}[18,19]$.

\subsection{Statistical analysis}

Data were analyzed on a personal computer running IBM-SPSS for windows "Statistical-Package for Social-Scientists" Release-22. Statistical tests were two-tailed. A p-value $<0.05$ was interpreted as statistically significant. For description of qualitative variables, the frequency distribution was utilized with tabulation including the number of cases and percentage. For description of measurable parameters, the mean, and standard-deviation were used to show central tendency and dispersion. Relations between categorical variables were tested by the Chi-Square Test (X2). Fishers' exact-test was utilized when the prerequisites of Chi-square test were violated.

\section{RESULTS}

From 320 Symptomatic patients, $44(13.8 \%)$ patients were positive for infection with $\mathrm{T}$. vaginalis and from 100 asymptomatic patients 5 (5\%)patient was positive for infection as shown in (Table 1.). There is high percent in the presence of T. vaginalis infection in symptomatic cases vs. asymptomatic cases $(13.8 \%$ vs. $5 \%$; 0.02 ), and the difference was statistically significant, the overall prevalence of $\mathrm{T}$. vaginalis among the studied cases was (11.7\%).

The mean age of studied cases as shown in Table 2 was $32 \pm 5.6$ years, $T$. vaginalis positive cases were more prevalent among age group 26-35 years (53.1\%). The difference between presence and absence of $T$. vaginalis among different age groups was of no statistically significant difference $(p=0.08)$.

As shown in (Table 3), (From 44 symptomatic (40 susceptible and 4 resistant) not include 5 cases which is asymptomatic) percent of typical type of discharge is higher in resistant than susceptible cases. The difference reveal high statistically significant difference (100\% vs. $7.5 \%$; $P=>0.001)$.

MANSOURA MEDICAL JOURNAL 
According to (Table 4), (From 44 symptomatic patients from which there was 1 patient widow and one patient divorced (40 susceptible and 4 resistant) not include 5 cases which is asymptomatic) post coital bleeding and pain were significantly higher in resistant cases.

Table 5 from total 49 positive symptomatic and asymptomatic cases, there was a high percent in presence of preterm delivery in resistant than susceptible cases $(50 \%$ vs. $2.2 \%$ ) and the difference was statistically significant $(p=0.015)$. Also, there was a high percent in presence of low birth weight infant in resistant than susceptible cases (50 vs. $4.4 \%$ ) and the difference was statistically significant $(p=0.03)$.

In the present study, MLC of different concentration of metronidazole under aerobic condition after 48 $\mathrm{h}$ incubation period as shown in Figure 3 was as following, most susceptible isolates $17 / 49$ (34.7\%)were sus- ceptible at MLC $1 \mu \mathrm{glml}$ followed by MLC $2 \mu \mathrm{g} \backslash \mathrm{ml}$ at which 8/49 (16.3\%) isolates were died, followed by $6 / 49$ $(12.2 \%)$ isolates at $4 \mu \mathrm{g} \backslash \mathrm{ml}$, followed by $7 / 49$ isolates $(14.2 \%)$ at $8 \mu \mathrm{glml}$, followed by $4 / 49$ isolates $(8.1 \%)$ at $16 \mu \mathrm{g} \backslash \mathrm{ml}$, followed by $3 / 49(6.1 \%)$ isolates at $32 \mu \mathrm{g} \backslash \mathrm{ml}$ while in resistant isolates 2 were died at concentration $64 \mu \mathrm{g} \backslash \mathrm{ml}$ and 2 isolates were died at concentration $128 \mu \mathrm{g} \backslash \mathrm{ml}$ and no isolates were died at concentration 256 uglml.

The prevalence of low-level metronidazole resistance was $(4.1 \%)$ and the prevalence of mild to moderate resistance was (4.1\%) according to Kissinger et al [19], degree of resistance was detected as follow, mild resistance occurs with MLCs of 50:100 $\mu \mathrm{g} / \mathrm{mL}$, mild-to moderate resistance occur with MLCs of 101:199 $\mu \mathrm{g} / \mathrm{mL}$, moderate resistance occurs with MLCs of $200: 400 \mu \mathrm{g} / \mathrm{mL}$ and high resistance occur with MLCs of $400 \mu \mathrm{g} / \mathrm{mL}$ of isolates. 
Marwa M. Hamouda et al...

Table 1 Detection rate of Trichomonas vaginalis among studied cases

\begin{tabular}{|l|l|l|l|l|}
\hline Group & Total No & Positive & $\%$ & P* \\
\hline Symptomatic Cases & 320 & 44 & $13.8 \%$ & \multirow{2}{*}{0.02} \\
\cline { 1 - 4 } Asymptomatic Cases & 100 & 5 & $5 \%$ & \\
\hline All cases included in the study & 420 & 49 & $11.7 \%$ & \\
\hline
\end{tabular}

*Chi Square test $\left(X^{2}\right)$

Table 2 Trichomonas vaginalis according to age groups of studied cases :

\begin{tabular}{|c|c|c|c|c|}
\hline Age group & $\begin{array}{l}\text { Trichomonas +ve } \\
\mathrm{N}(\%)\end{array}$ & $\begin{array}{l}\text { Trichomonas -ve } \\
\mathrm{N}(\%)\end{array}$ & Total number & P* \\
\hline $18-25$ & $9(18.3 \%)$ & $107(28.8 \%)$ & 116 & \multirow[t]{3}{*}{0.08} \\
\hline $26-35$ & $26(53.1)$ & $143(38.5 \%)$ & 169 & \\
\hline $36-45$ & $14(28.6)$ & $121(32.6 \%)$ & 135 & \\
\hline
\end{tabular}

${ }^{*}$ Chi Square test $\left(X^{2}\right)$

Table 3 Comparison of susceptible and resistant isolate of Trichomonas vaginalis symptomatic cases as regard presence of discharge and bad odor:

\begin{tabular}{|c|c|c|c|c|c|c|}
\hline & & \multicolumn{2}{|c|}{ Susceptible (40) } & \multicolumn{2}{|c|}{ Resistant (4) } & $\mathrm{P}^{* *}$ \\
\hline & & No & $\%$ & No & $\%$ & \multirow{3}{*}{$<0.001$} \\
\hline \multirow{2}{*}{ Discharge } & Typical & 3 & $7.5 \%$ & 4 & $100.0 \%$ & \\
\hline & Atypical & 37 & $92.5 \%$ & 0 & $0.0 \%$ & \\
\hline \multirow{2}{*}{ Bad odor } & Absent & 18 & $45.0 \%$ & 0 & $0.0 \%$ & \multirow{2}{*}{0.13} \\
\hline & Present & 22 & $55.0 \%$ & 4 & $100.0 \%$ & \\
\hline
\end{tabular}

**Fisher's Exact test 
IN VITRO BIOCHEMICAL VARIABILITY etc..

Table 4 : comparison of susceptible and resistant isolates of Trichomonas vaginalis symptomatic cases as regard other symptoms:

\begin{tabular}{|c|c|c|c|c|c|c|}
\hline & & Sus & ible (40) & Resi & (4) & \\
\hline & & No & $\%$ & No & $\%$ & \\
\hline Itching & Absent & 16 & $40.0 \%$ & 0 & $0.0 \%$ & 0.28 \\
\hline & Present & 24 & $60.0 \%$ & 4 & $100.0 \%$ & \\
\hline Burning & Absent & 15 & $37.5 \%$ & 0 & $0.0 \%$ & 0.28 \\
\hline & Present & 25 & $62.5 \%$ & 4 & $100.0 \%$ & \\
\hline Dyspareunia & Absent & 19 & $50.0 \%$ & 0 & $0.0 \%$ & 0.11 \\
\hline & Present & 19 & $50.0 \%$ & 4 & $100.0 \%$ & \\
\hline Post coital & Absent & 35 & $92.1 \%$ & 1 & $25.0 \%$ & 0.007 \\
\hline bleeding & Present & 3 & $7.9 \%$ & 3 & $75.0 \%$ & \\
\hline Dysuria & Absent & 19 & $47.5 \%$ & 1 & $25.0 \%$ & 0.61 \\
\hline & Present & 21 & $52.5 \%$ & 3 & $75.0 \%$ & \\
\hline Pain & Absent & 24 & $60.0 \%$ & 0 & $0.0 \%$ & 0.03 \\
\hline & Present & 16 & $40.0 \%$ & 4 & $100.0 \%$ & \\
\hline
\end{tabular}

**Fisher's Exact test

Table 5 : comparison of susceptible and resistant of Trichomonas vaginalis positive cases as regard obstetric history:

\begin{tabular}{|c|c|c|c|c|c|c|}
\hline & & \multicolumn{2}{|c|}{ Susceptible cases (45) } & \multicolumn{2}{|c|}{ Resistant cases (4) } & \multirow{2}{*}{$\mathbf{P * *}$} \\
\hline & & No & $\%$ & No & $\%$ & \\
\hline \multirow[t]{2}{*}{ Parity } & Nulliparous & 14 & $31.1 \%$ & 0 & $0.0 \%$ & \multirow[t]{2}{*}{0.31} \\
\hline & Has Children & 31 & $68.9 \%$ & 4 & $100.0 \%$ & \\
\hline \multirow[t]{2}{*}{ Preterm } & Absent & 44 & $97.8 \%$ & 2 & $50.0 \%$ & \multirow[t]{2}{*}{0.015} \\
\hline & Present & 1 & $2.2 \%$ & 2 & $50.0 \%$ & \\
\hline \multirow[t]{2}{*}{ Abortion } & Absent & 43 & $95.6 \%$ & 3 & $75.0 \%$ & \multirow[t]{2}{*}{0.22} \\
\hline & Present & 2 & $4.4 \%$ & 1 & $25.0 \%$ & \\
\hline \multirow{2}{*}{$\begin{array}{l}\text { Low Birth } \\
\text { Weight }\end{array}$} & Absent & 43 & $95.6 \%$ & 2 & $50.0 \%$ & \multirow[t]{2}{*}{0.03} \\
\hline & Present & 2 & $4.4 \%$ & 2 & $50.0 \%$ & \\
\hline
\end{tabular}

**Fisher's Exact test

Vol. 43, No. 1 \& 2 Jan. \& April, 2014 


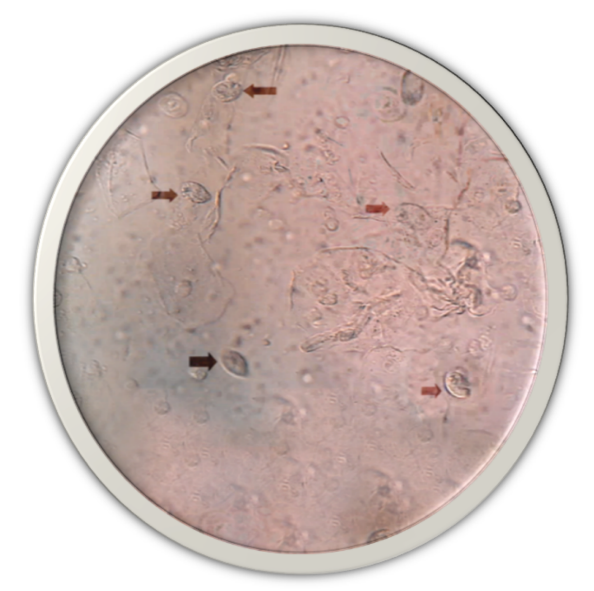

Figure. 1: Shows T. vaginalis trophozoite in wet mount preparation

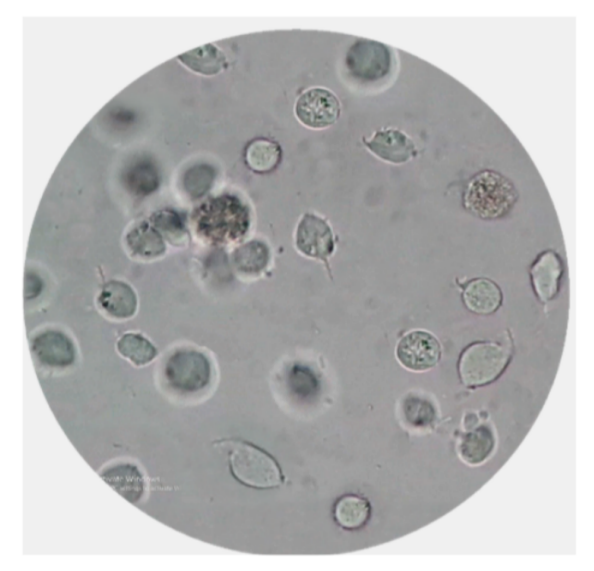

Figure. 2: T. vaginalis observed in Modified Diamond's culture

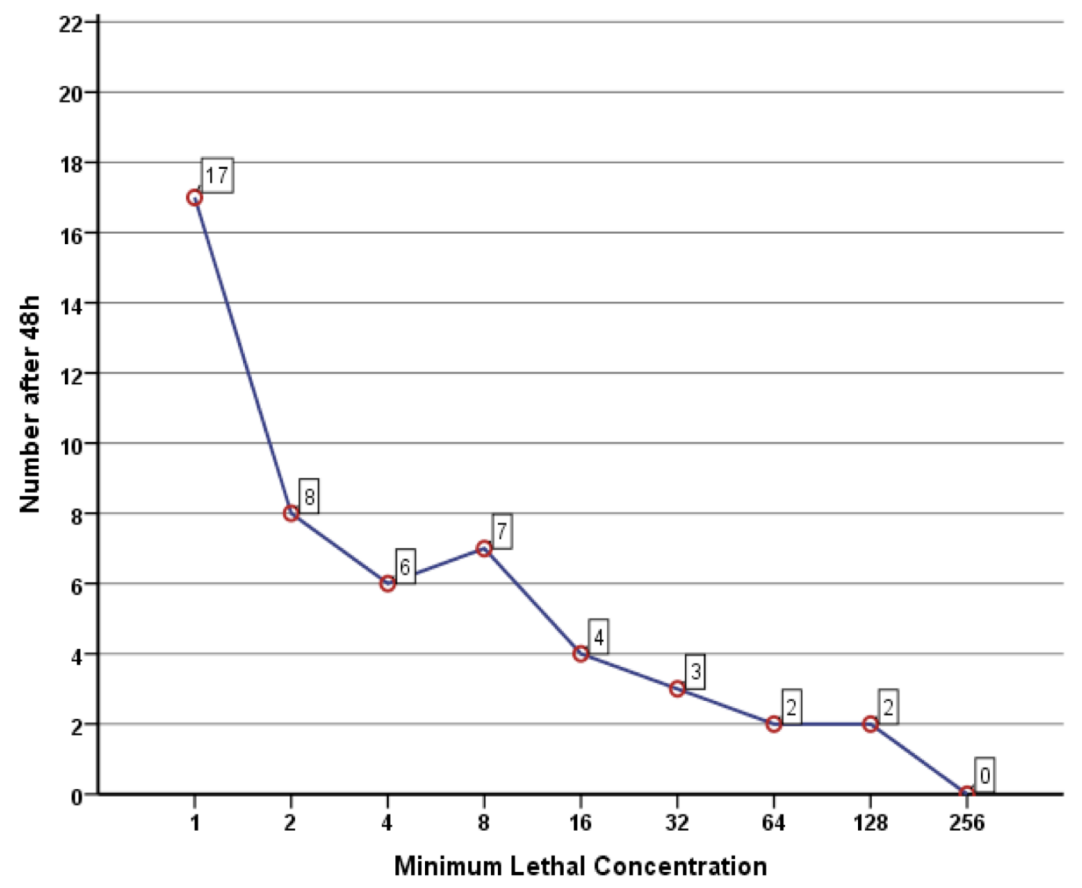

Figure 3 Minimal lethal concentrations of metronidazole on T. vaginalis isolates.

MANSOURA MEDICAL JOURNAL 


\section{DISCUSSION}

Trichomonas vaginalis is a parasite of the urogenital tract of human, with a worldwide occurrence and significant implications for global public health. It has been implicated with preterm labor, pelvic inflammatory disease, cervical intraepithelial neoplasia [20].

The overall prevalence of $\mathrm{T}$. vaginalis among women included in this study was $11.7 \% \quad(49 / 420)$, among symptomatic woman was $13.8 \%(44 / 320)$ and among asymptomatic woman was $5 \%(5 / 100)$. This corroborates findings by a previous study from Benha the prevalence of $\mathrm{T}$. vaginalis in this study was $11 \%$, [21]. However, higher rates of infection were recorded in Cairo and Mansoura with prevalence of $23 \%$ and $38.37 \%$, respectively [22, 23]. On the other side, studies from Africa, Iraq and Cairo demonstrated a lower prevalence of $T$. vaginalis infection ranging from $4.1 \%-5.4 \%[14,24,25]$

The variations in the prevalence of infection related to many factors including age, sexual activity, number of sexual partners, other sexually transmitted diseases, menstrual cycle phases, examination techniques, specimen collection, sample size, inclusion and exclusion criteria and laboratory technique. Also, may be due to socio-demographic characters of the communities that change from a country to another and from a society to another [26].

In this study the Infection was considerably more common in symptomatic than in asymptomatic women with statistically significant difference (13.8\% vs. 5\%; P0.02), and this finding matched with other study [27]

The mean age of studied cases was $32 \pm 5.6$ years, T. vaginalis positive cases were more prevalent among age group 26-35 years (53.1\%), followed by age group 3645 years $(28.6 \%)$, followed by age group $18-25$ years (18.3\%).

In the present study, percent of typical type of discharge is higher in resistant than susceptible cases and the difference was of high statistical significance $(100 \%$ vs. $7.5 \%$; $\mathrm{P}=>0.001$ ), also there was a high percent in the presence of post coital bleeding in resistant versus susceptible cases and the difference between was statistically significant (7.9\% vs. $75 \% ; P=0.007$ ), also there 
was a high percent in the presence of lower abdominal pain in resistant versus susceptible cases and the difference between was statistically significant ( $40 \%$ vs. $100 \% ; P=0.03)$, also there was a high percent in presence of low birth weight infant in resistant than susceptible cases (50 vs. $4.4 \%$ ) and the difference between was statistically significant $(p$ $=0.03$ )

To our Knowledge this is the first study to compare the susceptible and resistant isolates of $T$. vaginalis from the previous point of view and from this result it will be a valuable finding used to suspect resistant $T$. vaginalis isolates in patient with profuse frothy yellow to gray malodourous discharge [28], post coital bleeding, lower abdominal pain, history of preterm delivery and low birth weight infant especially if all present in combination.

According to Narcisi and Secor [18], in an aerobic 48 hours assay in the present study $T$. vaginalis isolates with MLC of $32 \mu \mathrm{g} / \mathrm{ml}$ and less were considered susceptible to metronidazole, while those with MLC of $64 \mu \mathrm{g} / \mathrm{ml}$ and greater were considered resistant.
From the previous finding the prevalence of resistance in our study was $8.2 \%$, this finding correlate with other study in US where $9.6 \%$ only were resistant to metronidazole among total Trichomoniasis cases [11]. Variation in susceptibility was also reported in other studies [29].

The prevalence of low-level metronidazole resistance was $(4.1 \%)$ and the prevalence of mild to moderate resistance was $(4.1 \%)$, this was in agreement with other study as regard low level resistance [30].

\section{Conclusion}

- T. vaginalis resistance to metronidazole is an announcing problem in the world, the incidence rate of metronidazole resistance is $8.2 \%$ in our locality.

- The presence of typical discharge, pain and post-coital bleeding point are significantly associated with resistance to metronidazole.

- T. vaginalis resistance to metronidazole is associated with significantly higher obstetric complications including preterm labor and low birth weight.

- It is recommended to do a pharmacokinetic study of metronida-

MANSOURA MEDICAL JOURNAL 
IN VITRO BIOCHEMICAL VARIABILITY etc...

zole to detect its level in the vaginal mucosa; a concentration higher than $64 \mathrm{ug} / \mathrm{ml}$ at 48 hours is needed to overcome resistance.

- Searching for another drug in T. vaginalis resistance should be considered in this prospect.

\section{REFERENCES}

1. Satterwhite, C.L., et al. (2013) : Sexually transmitted infections among US women and men: prevalence and incidence estimates, 2008. Sex Transm Dis,. 40(3): p. 187-93.

2. World Health Organisation. (2008) : Global incidence and prevalence of selected curable sexually transmitted infections 2012; Available from: http:// www.who.int/reproductivehealth/ publications/rtisSTI-estimates. pdf.

3. Hegazi, M.M., et al. (2009) : Polymerase chain reaction versus conventional methods in the diagnosis of vaginal trichomoniasis. J Egypt Soc Parasitol,. 39(1): p. 1121.

Vol. 43, No. 1 \& 2 Jan. \& April, 2014
4. Sherrard, J., et al., (2011) : uropean (IUSTI/WHO) guideline on the management of vaginal discharge, 2011. Int J STD AIDS, 2011. 22(8): p. 421-9.

5. Byun, J.M., et al. (0215) : Experience of successful treatment of patients with metronidazole-resistant Trichomonas vaginalis with zinc sulfate: A case series. Taiwan J Obstet Gynecol, 54(5): p. 617-20.

6. Coleman, J.S., C.A. Gaydos, and F. (2013) : Witter, Trichomonas vaginalis vaginitis in obstetrics and gynecology practice: new concepts and controversies. Obstet Gynecol Surv,. 68(1): p. 43-50.

7. Huppert, J.S., et al. (2007) : Rapid antigen testing compares favorably with transcription-mediated amplification assay for the detection of Trichomonas vaginalis in young women. Clinical Infectious Diseases,. 45(2): p. 194-198. 
8. Marlowe, E.M., et al. (2011) : Evaluation of the Cepheid Xpert MTB/RIF Assay for Direct Detection of Mycobacterium tuberculosis Complex in Respiratory Specimens. Journal of Clinical Microbiology,. 49(4): p. 1621-1623.

9. Darani, H.Y., et al. (2010) : Development of a Latex Agglutination Test as a Simple and Rapid Method for Diagnosis of T. Infection. Avicenna $J$ Med Biotechnol,. 2 (1): p. 636.

10. Bachmann, L.H., et al. (2011) : Trichomonas vaginalis genital infections: progress and challenges. Clin Infect Dis,. 53 Suppl 3: p. S16072.

11. Schwebke, J.R. and F.J. (2006) : Barrientes, Prevalence of Trichomonas vaginalis isolates with resistance to metronidazole and tinidazole. Antimicrob Agents Chemother,. 50 (12): p. 4209-10.
12. Cudmore, S.L., et al. (2004) : Treatment of infections caused by metronidazoleresistant Trichomonas vaginalis. Clin Microbiol Rev,. 17(4): p. 783-93, table of contents.

13. Nyirjesy, P., J. Gilbert, and L.J. (2011) : Mulcahy, Resistant trichomoniasis: successful treatment with combination therapy. Sex Transm Dis,. 38(10): p. 962-3.

14. Mahmoud, A., et al. (2015) : Prevalence of Trichomonas vaginalis infection among Egyptian women using culture and Latex agglutination: cross-sectional study. BMC Womens Health,. 15: p. 7.

15. Fouts, J. and C. (1980) : Fogel, A survey of obstetrical teaching strategies in baccalaureate schools of nursing. J Nurs Educ,. 19(7): p. 18-26.

16. Meri, T., et al. (2000) : Resistance of Trichomonas vaMANSOURA MEDICAL JOURNAL 
IN VITRO BIOCHEMICAL VARIABILITY etc...

ginalis to metronidazole: report of the first three cases from Finland and optimization of in vitro susceptibility testing under various oxygen concentrations. J Clin Microbiol,. 38(2): p. 763-7.

17. Kulda, J., et al. (1982) : Metronidazole resistance of Trichomonas vaginalis as a cause of treatment failure in trichomoniasis--A case report. $\mathrm{Br} \mathrm{J}$ Vener Dis,. 58 (6): p. 394-9.

18. Narcisi, E.M. and W.E. (1996) : Secor, In vitro effect of tinidazole and furazolidone on metronidazole-resistant Trichomonas vaginalis. Antimicrob Agents Chemother,. 40(5): p. 1121-5.

19. Kissinger, P., et al. (2008) : Early repeated infections with Trichomonas vaginalis among HIV-positive and HIV-negative women. Clin Infect Dis,. 46(7): p. 994-9.

20. Conrad, M.D., et al. (2013) : Getting trichy: tools and ap- proaches to interrogating Trichomonas vaginalis in a post-genome world. Trends Parasitol,. 29(1): p. 17-25.

21. Hussein, A.H., et al. (2015) : Prevalence, Clinical Criteria and Sociodemographic Predictors of Trichomonas vaginalis Infection in Suspected Egyptian Women, Using Direct Diagnostic Techniques. Iran J Parasitol,. 10(3): p. 432-40.

22. Negm, A.Y. and D.A. (2004) : el-Haleem, Detection of trichomoniasis in vaginal specimens by both conventional and modern molecular tools. J Egypt Soc Parasitol,. 34(2): p. 589-600.

23. Hegazy, M.M., et al. (2012) : Performance of rapid immunochromatographic assay in the diagnosis of Trichomoniasis vaginalis. Diagn Microbiol Infect Dis,. 74(1): p. 49-53.

24. Van Der Pol, B., et al. (2008) : Trichomonas vaginalis infection and human immu- 
nodeficiency virus acquisition in African women. $J$ Infect Dis,. 197(4): p. 54854.

25. Silva, L.C., et al. (2013) : Trichomonas vaginalis and associated factors among women living with HIV/ AIDS in Amazonas, Brazil. Braz J Infect Dis,. 17(6): p. 701-3.

26. Fernando, S.D., et al. (2012) : Clinical features and sociodemographic factors affecting Trichomonas vaginalis infection in women attending a central sexually transmitted diseases clinic in Sri Lanka. Indian J Sex Transm Dis,. 33(1): p. 2531.

27. Ton Nu, P.A., et al. (2015) : Prevalence of Trichomonas vaginalis infection in symptomatic and asymptomatic women in Central Vietnam. J Infect Dev Ctries,. 9(6): $p$. 655-60.

28. Petrin, D., et al. (1998) : Clinical and microbiological aspects of Trichomonas vaginalis. Clin Microbiol Rev,. 11(2): p. 300-17.

29. El-Okbi, L.M., et al. (2004) : Growth patterns and antigenic analysis of Egyptian Trichomonas vaginalis isolates. J Egypt Soc Parasitol,. 34(3): p. 841-55.

30. Kirkcaldy, R.D., et al. (2012) : Trichomonas vaginalis antimicrobial drug resistance in 6 US cities, STD Surveillance Network, 2009-2010 Emerg Infect Dis,. 18(6): p. 939-43. 